\title{
Effectiveness of interventions aimed at improving physical and psychological outcomes of fall-related injuries in people with dementia: a narrative systematic review
}

\author{
Shannon Robalino ${ }^{1,2^{*}}$ (D), Sarange B. Nyakang' ${ }^{2}$, Fiona R. Beyer ${ }^{2}$, Chris Fox ${ }^{3,4}$ and Louise M. Allan ${ }^{5}$
}

\begin{abstract}
Background: The annual prevalence of falls in people with dementia ranges from 47 to $90 \%$. Falls are a common reason for hospital admission in people with dementia, and there is limited research evidence regarding the care pathways experienced by this population. In addition to immediate management of an injury, prevention of further falls is likely to be an important part of any successful intervention.

This review aims to assess the effectiveness of interventions for improving the physical and psychological wellbeing of people with dementia who have sustained a fall-related injury.

Methods: Systematic review methodologies were employed utilising searches across multiple databases (MEDLINE, CENTRAL, Health Management Information Consortium, EMBASE, CINAHL, Web of Science, Allied and Complementary Medicine Database, and Physiotherapy Evidence Database (PEDro)) and citation chaining. Studies including people with a known diagnosis of dementia living in the community and who present at health services with a fall, with or without injury, were included. Outcomes of interest included mobility, recurrent falls, activities of daily living, length of hospital stay, and post-discharge residence. Results were independently reviewed and quality assessed by two researchers, and data extracted using a customised form. A narrative synthesis was performed due to heterogeneity of the included studies.

Results: Seven studies were included. Interventions clustered into three broad categories: multidisciplinary in-hospital postsurgical geriatric assessment; pharmaceuticals; and multifactorial assessment. Multidisciplinary care and early mobilisation showed short-term improvements for some outcomes. Only an annual administration of zoledronic acid showed long-term reduction in recurrent falls.

Conclusions: Due to high heterogeneity across the studies, definitive conclusions could not be reached. Most post-fall interventions were not aimed at patients with dementia and have shown little efficacy regardless of cognitive status. Minor improvements to some quality of life indicators were shown, but these were generally not statistically significant. Conclusions were also limited due to most studies addressing hip fracture; the interventions provided for this type of injury may not be suitable for other types of fractures or soft tissue injuries, or for use in primary care.
\end{abstract}

Systematic review registration: PROSPERO CRD42016029565.

Keywords: Accidental falls, Dementia, Fractures, Geriatrics, Narrative reviews, Soft tissue injuries

\footnotetext{
* Correspondence: Shannon.C.Robalino@kpchr.org

1 Present Address: Kaiser Permanente Research Affiliates, Evidence-based

Practice Center, Center for Health Research, Portland, OR, USA

${ }^{2}$ Institute of Health and Society, Newcastle University, Newcastle upon Tyne, UK

Full list of author information is available at the end of the article
} 


\section{Background}

In 2014, an estimated 850,000 people were living with dementia in the United Kingdom [1], 70\% of whom were living in their own homes [2]. The annual prevalence of falls in people with dementia (PWD) ranges from 47 to $90 \%[3,4]$, depending on dementia subtype; those living in their own home sustain almost 10 times more incident falls than those with a cognitive impairment, and their falls are more likely to be injurious [4]. Dementia is an independent risk factor for experiencing a serious injury (e.g. fracture or head injury) related to a fall [4]. A recent Australian study indicates the most common fracture-related injury in dementia patients is to the hip followed by the trunk [5]. Other common serious injuries not resulting in a fracture in PWD include those to the head and neck, lower limbs, and traumatic brain injury [5]. Compared to other patients, PWD are typically at greater risk of hospitalisation, prolonged hospital stays, increased care demands, and incomplete recovery after a fall [6].

Dementia is generally initially assessed with cognitive screening tests (e.g. the Mini Mental State Exam (MMSE)) and performance of Activities of Daily Living (ADLs) (e.g. bathing, dressing, mobility). Depending on the outcomes of these assessments, a diagnosis may be given ranging from mild to moderate to severe. Mild forms of dementia indicate the person can perform most ADLs without assistance while a person with severe dementia may be completely dependent on a carer to perform all ADLs.

There is limited research evidence regarding the care pathways experienced by PWD presenting with a fallrelated injury, although it is known that falls are a common reason for hospital admission in people with dementia [7] with a third of those sustaining only soft tissue injuries, not fractures $[5,8]$. Comorbid factors are more likely to be present in people with dementia [9] and include an underlying acute medical cause of the fall, delirium, inability to mobilise, and carer stress or lack of ability to support them after the fall. Up to $40 \%$ of people presenting to the emergency services (ES) have a cognitive disorder [10], which is a barrier to good emergency care thereby resulting in preventable admissions. A recent review found that the evidence underpinning the management of PWD in the ES reflects expert opinion rather than controlled trials [10], and there is a paucity of evidence-based pathways for hospital care [11]. Staff often perceives PWD as less capable of rehabilitation due to lack of person-centred supportive strategies [12]. PWD presenting to ES and those admitted to hospital are therefore currently managed using services not designed to meet their needs; we believe a successful intervention would improve care in the ES and may reduce or shorten hospital admissions.

Furthermore, some PWD with fall-related injuries may not present to ES or may present directly to primary care, and a majority of injuries sustained are minor soft tissue injuries which may not require medical attention [4]. A successful intervention must therefore also work for PWD whose care is managed in the community. Improvements in the management of fallrelated injuries might reduce further complications for PWD and carers by improving physical recovery, ameliorating fear of falling, and psychological morbidity [13], all of which may lead the person to restrict their mobility. Restriction of mobility results in deconditioning and a cycle of further loss of mobility and frailty.

In addition to immediate management of an injury, prevention of further falls is likely to be an important part of any successful intervention. For older people without dementia, it has been reported that a multifactorial intervention by a specialist falls service will prevent further falls $[14,15]$. Although the components of such an intervention are usually directed at known risk factors for falls, these methods have not been shown to be consistently effective in PWD [16] and indeed there are trials which have shown no benefit $[17,18]$. The primary reasons for this may be that risk factors for falls may differ in PWD or be more frequent in or specific to dementia, e.g. wandering [19], Parkinsonism [20, 21], severity of cognitive impairment [20], and functional impairment [22].

In summary, PWD have complex needs which are not fully met by existing services. Several recent reviews address fall risk and fall prevention in cognitively impaired older people and PWD [16, 23-26]. The aim of this paper is to perform a systematic review and meta-analysis of the current research evidence for effectiveness of interventions intended to improve the physical and psychological wellbeing of PWD who have sustained a fall-related injury of any kind. The primary outcomes of interest are measures of performance-oriented assessment of mobility (e.g. Tinetti score) and measures of performance in ADLs (e.g. Barthel score). Secondary outcomes of interest are length of hospital stay, place of discharge post-intervention, recurrent fall or injury, and readmission to hospital. We are interested in measures up to 3 months post-intervention though timings are variable based on what is reported in the studies. This review also forms part of a larger study funded by the National Institutes of Health Research on the development of a complex intervention to improve the outcome of fallrelated injuries in PWD living in their own homes.

\section{Methods}

Protocol and registration

The protocol for this review was registered with PROSPERO (CRD42016029565) [27]. The review is described according 
to PRISMA guidelines [28] and the PRISMA checklist is available in Additional file 1.

\section{Search strategy and selection criteria}

Table 1 provides an overview of the search methods and selection criteria. Databases were searched from inception to the reported search date. An update search in January 2018 of Medline only was conducted due to limited resources and evidence that Medline generally provides the largest yield of included studies [29]. A sample Medline search strategy is available in Additional file 2.

Citation chaining was used for included papers and relevant systematic reviews to identify additional papers of interest. Grey literature was not included due to limited resources. Citations were stored in EndNote.

Following Cochrane principles, two reviewers (SR and FRB) independently screened titles and abstracts to identify potentially relevant papers. Disagreements were resolved through discussion and where necessary with a third reviewer (LMA or CF). For studies taken forward to full-text review, two reviewers (SR and FRB) screened the full text to determine inclusion or exclusion of the study; discrepancies were resolved through discussion or by a third reviewer (LMA or CF).

Table 1 Search methods including databases and dates of searches, search term facets, limitations, and inclusion/exclusion criteria

Databases searched (inception MEDLINE, CENTRAL, Health through November 2015, Management Information Consortium, Medline update January 2018) EMBASE, CINAHL, Web of Science, Allied and Complementary Medicine Database, Physiotherapy Evidence Database (PEDro), Clinicaltrials.gov, ISRCTN registry

Search facets and limits*_ Facets: dementia, falls and fall-related injuries, and interventions Limits: English language and RCT filters [47] applied when possible

Inclusion criteria

Design: RCT or quasi-experimental Population: PWD living in the community having sustained a fall, with or without injury Intervention: any type of intervention directed at people with dementia who have fallen including multifactorial assessment or intervention Comparisons: usual care Outcomes: measures of performanceoriented assessment of mobility, ADLs, length of hospital stay, place of discharge, recurrent fall or injury, and hospital readmission

Exclusion criteria

\section{Data extraction}

Data were extracted using a bespoke Excel form by one reviewer (SR) and were checked by a second (SBN). Discrepancies were resolved through discussion. Data collected included details of the study population (e.g. MMSE score), setting (e.g. ward), the intervention (e.g. care team, services used) and comparator, and outcomes (e.g. mobility, length of hospital stay) measured at baseline and follow-up. For studies that satisfied inclusion criteria but whose reported outcomes were incomplete, authors were contacted three times via email to provide additional data.

\section{Quality assessment}

The Cochrane Risk of Bias tool [30] was used to assess methodological quality within and across studies. Two reviewers (SR and SBN) independently assessed each study. Studies were assessed across five domains of bias and deemed to be at high-, low-, or unclear risk of bias on each domain. Disagreements were discussed and where necessary a third reviewer (FRB) was consulted.

\section{Data synthesis}

We planned to perform a meta-analysis, but study heterogeneity made this impractical. Few studies measured the same outcomes, and even where these outcomes were similar enough to warrant comparison, their measurement tools varied, thereby precluding a valid statistical analysis. Therefore, we carried out a narrative synthesis broadly categorising studies by intervention and presenting detailed results by outcomes of interest.

\section{Results}

\section{Study selection}

The PRISMA flow diagram in Fig. 1 provides a summary of the study selection process. Seven studies were selected for inclusion.

\section{Study characteristics}

This review included six RCTs $[18,31-35]$ and one quasi-experimental study [36] (see Table 2 for detailed characteristics). Studies were conducted in the United Kingdom [18, 35], Canada [36], Finland [31], Norway [34], Sweden [33], and one which included 24 countries [32]. All studies included both cognitively intact and diagnosed dementia patients $(n=1061)$ with the exception of Shaw [18], which recruited patients on the basis of a Mini Mental State Exam (MMSE) score of $<24$ indicating at least mild dementia was present.

Participants' cognitive status was assessed using the MMSE [18, 31, 33, 34, 36] or the Short Portable Mental Status Questionnaire (SPMSQ) [32, 35]. Only one study included a clinical diagnosis of dementia [33]. Most patients 


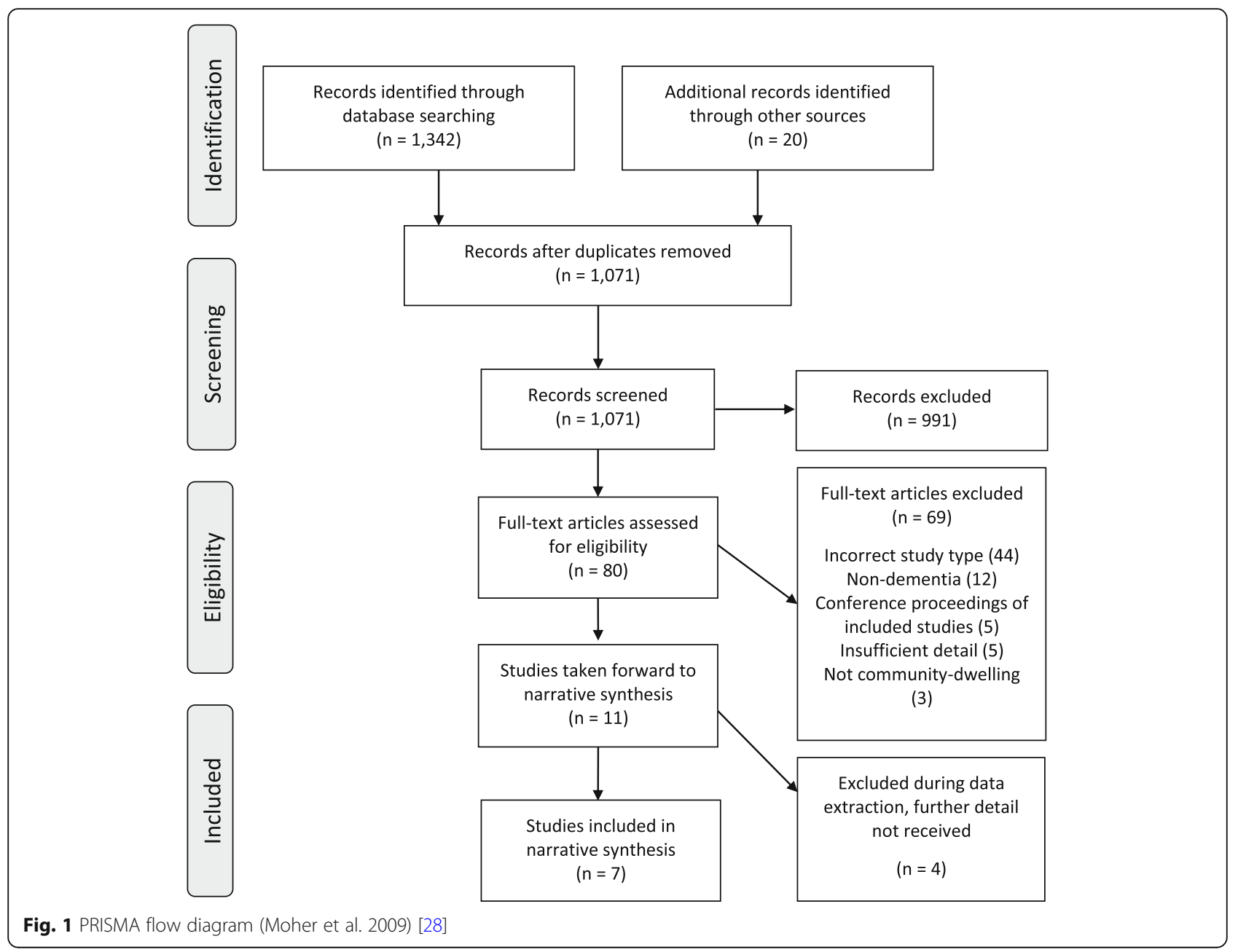

in the included studies presented with, and were treated for, hip fracture. Six of the seven studies had patients aged $\geq 65$ years (range 78 to 84 years); most of the patients in the studies were female.

Most of the interventions took place in a hospital [31, 33-36], and one in an A\&E department [18]. For one study this was unclear, but appeared to be a clinical setting due to the nature of the intervention [32].

The interventions can be considered in three broad categories:

1) Multidisciplinary in-hospital post-surgical geriatric assessment (five studies [31, 33-36]): these varied in terms of the type of ward (e.g. geriatric versus orthopaedic), mix of staff from multiple disciplines, and components of the intervention. All studies in this group included a core team of a geriatrician, nurse, occupational therapist, and physiotherapist. The studies also included a variety of other staff that were either part of the core team or available depending on the needs of the patient. For example, one study included a social worker as a core team member [31] while Watne et al. [34] had a social worker available as needed. Other staff included a dietician [33], neuropsychologist [31], and a general practitioner (GP) [31, 35]. The actual components of the assessments and interventions also differed, but all assessments and interventions occurred in the hospital setting. For example, early discharge planning was conducted in three studies [31, 34, 36], post-discharge home visits in two [31,33], and weekly team meetings in three $[31,33,35]$. Full details of the assessments and interventions across these studies can be found in Additional file 3.

2) Pharmaceutical: one study [32] administered an annual dose of intravenous zoledronic acid to participants in an attempt to reduce recurrent falls and further fractures by improving bone health.

3) Multifactorial assessment and intervention: one study [18] performed multifactorial assessments and interventions in patients presenting at an $\mathrm{A} \& \mathrm{E}$ Department post-fall. The multifactorial assessment involved a multidisciplinary team similar to the inhospital geriatric assessment and followed up with 


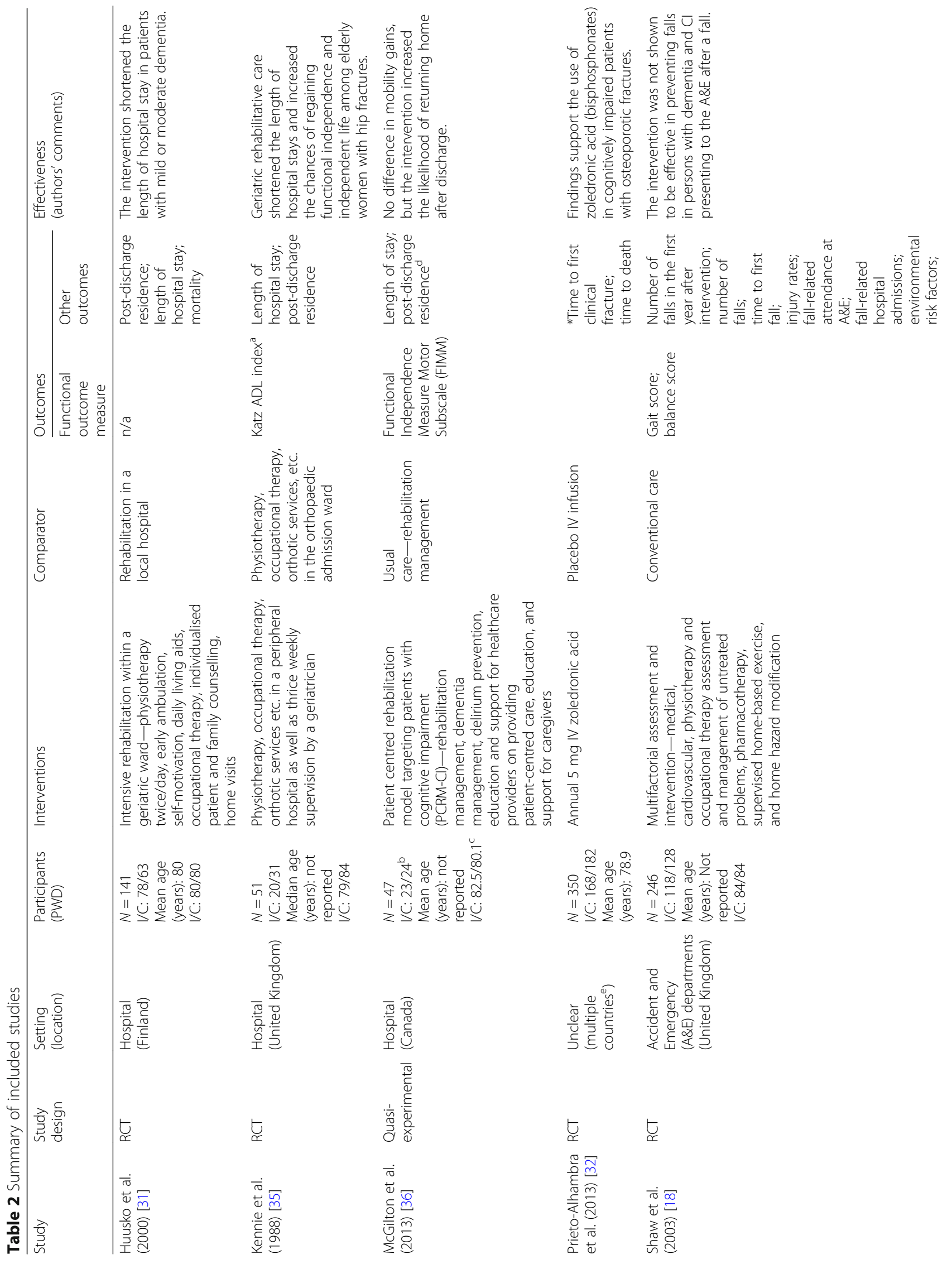




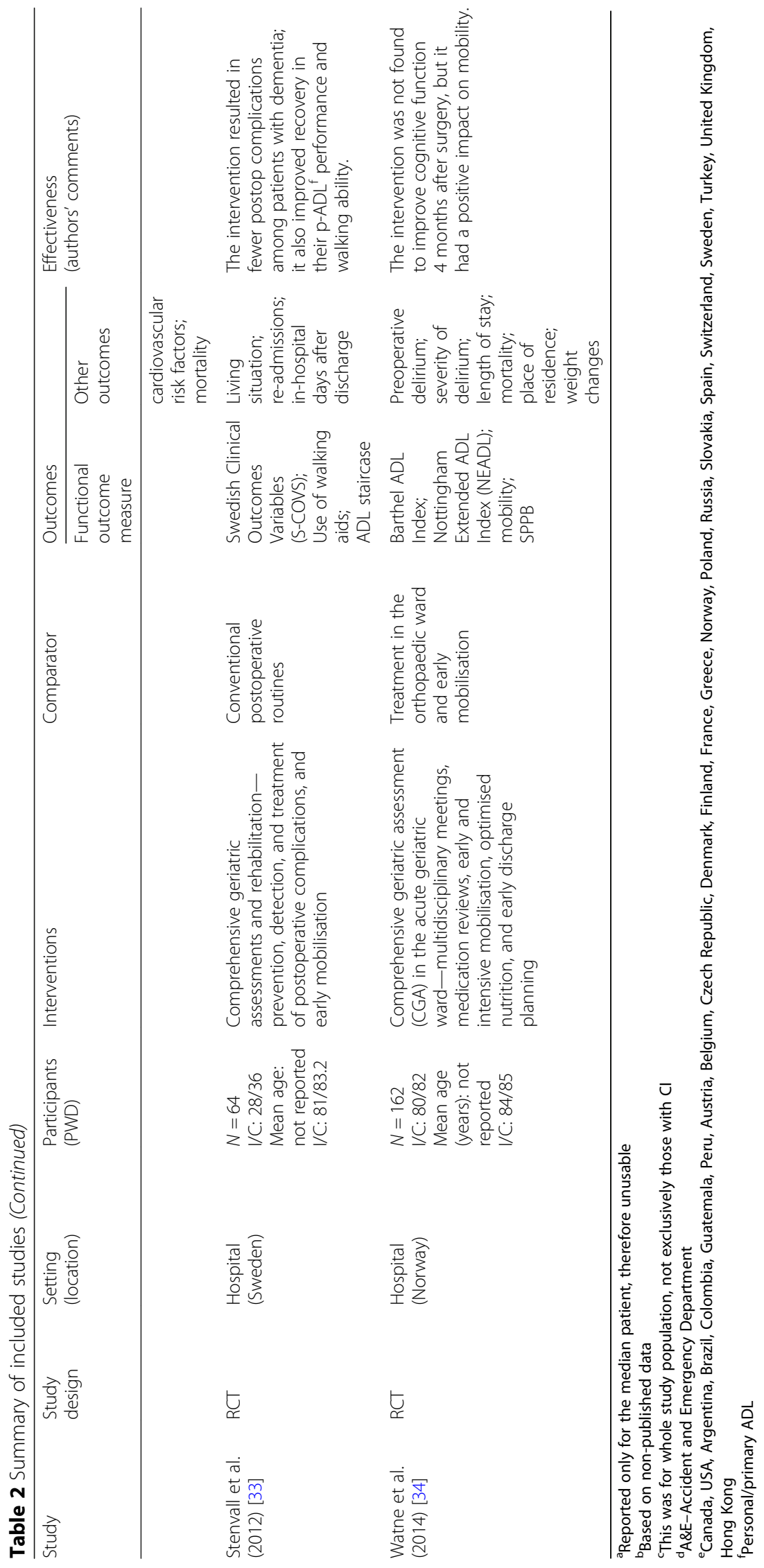


risk assessments in patients' homes. Patients were offered a variety of interventions based on the risk assessments such as home-based exercise, home hazard modification, medication review, and optical correction by an optician.

None of the studies reported psychological outcomes.

\section{Synthesis of results}

Reported outcomes were highly variable with little overlap in terms of the outcomes measured or the tools used to measure them. Most studies reported place of residence after discharge and a measure of either mobility or ADLs. Table 3 provides a summary view of the studies grouped by our categorisation and outcomes of interest reported.

\section{Mobility}

Four studies reported different measures of mobility following the intervention $[18,33,34,36]$, of which three reported limited improvement or retention of mobility in the intervention group compared to control. Those studies utilising multidisciplinary in-hospital post-surgical geriatric assessment $[33,34,36]$ found short-term improvements in gait, but long-term improvements were either not reported or proved statistically insignificant. It should be noted that studies used different mobility scales, and these scales have relatively little overlap in components measured.

\section{Recurrent fall, injury, or other fall-related outcome}

Three studies reported recurrent falls post-intervention $[18,32,33]$, of which only one [33] reported a reduction in in-patient falls in the treatment group (4\%) compared to control $(31 \%, p=0.006)$, although there was no difference in new fractures. A second study [18] reported no difference in the number of patients with falls, the median number of falls, or the median number of weeks before first recurrent fall. The final study [32] found no difference in falls for PWD, but reported a reduction in recurrent fractures at 6 months in the cognitively impaired patients.

\section{Activities of daily living}

Three studies reported on post-intervention ADLs [33-35] utilising four different tools: the Nottingham Extended ADL Index (NEADL); the Barthel Activities of Daily Living (BADL); personal/primary ADL (P-ADL); and the staircaseADL. These four scales have limited overlap with only two items common among them (feeding and transferring).

These studies all used multidisciplinary in-hospital post-surgical geriatric assessment and intervention and reported ADLs post-intervention; however, the results are mixed and therefore inconclusive. Two of the studies $[34,35]$ did not provide baseline ADL assessments though both stated some improvements to those in the cognitively impaired groups. The third study [33] found a larger proportion of those in the treatment group had regained pre-fall ADL levels at 12 months postintervention $(p=0.027)$.

\section{Length of hospital stay}

Three studies measured length of hospital stay [31, 34, 35]. All three studies used multidisciplinary in-hospital postsurgical geriatric assessment as an intervention, but the components of those services were variable. They provided some indication that multidisciplinary in-hospital postsurgical geriatric assessment and intervention decreases length of stay for those with mild or moderate dementia.

One study [31] reported length of hospital stay categorised by MMSE scores. ${ }^{1}$ Those in the mild dementia group had a median length of stay of 29 days (range 16138 ) and 46 days (range 10-365) for the intervention and control groups, respectively $(p=0.002)$. For moderate dementia, the median length of stay was 47 days (range 10-365) and 147 days (range 18-365) for the intervention and control groups, respectively $(p=0.042)$. The authors therefore concluded that their intervention could reduce length of stay for patients with mild or moderate dementia. However, for severe dementia, the difference in length of stay between the groups was not significant $(p=0.902)$.

Similarly, Kennie et al. [35] reported length of stay based on SPMSQ score at study entry in clusters of general mental status and reported a shorter length of stay in all treatment groups, regardless of mental state.

The intervention group in Watne et al. [34] had a significantly longer median length of stay, 11 days (IQR 6-14) versus 8 days (IQR 3-10) in the control group $(p \leq 0.001)$.

\section{Place of residence following discharge}

Five studies reported on place of discharge following the intervention [31, 33-36], but the results were contradictory. All five studies utilised multidisciplinary in-hospital post-surgical geriatric assessment. Three studies [31, 35, 36] found patients with moderate dementia in the treatment group were more likely to return to independent living. The remaining studies $[33,34]$ showed no significant difference in independent living between treatment and control groups regardless of severity of dementia.

\section{Readmission to hospital}

Readmissions to hospital related to the index fall were reported by two studies $[18,34]$. Neither study showed a statistically significant difference in readmission rates between the treatment and control groups with dementia at 4- and 12-months. 
Table 3 Summary table of interventions and reported outcomes of interest

\begin{tabular}{|c|c|c|c|c|c|c|}
\hline Studies (grouped by broad intervention) & Mobility & $\begin{array}{l}\text { Recurrent fall, injury, or other } \\
\text { fall-related }\end{array}$ & $\begin{array}{l}\text { Activities of } \\
\text { daily living }\end{array}$ & $\begin{array}{l}\text { Length of } \\
\text { hospital stay }\end{array}$ & $\begin{array}{l}\text { Place of residence } \\
\text { following discharge }\end{array}$ & $\begin{array}{l}\text { Readmission } \\
\text { to hospital }\end{array}$ \\
\hline \multicolumn{7}{|c|}{ Multidisciplinary in-hospital post-surgical geriatric assessment } \\
\hline Huusko 2000 [31] & & & & $\checkmark$ & $\checkmark$ & \\
\hline Stenvall 2012 [33] & $\checkmark$ & $\checkmark$ & $\checkmark$ & & $\checkmark$ & \\
\hline Watne 2014 [34] & $\checkmark$ & & $\checkmark$ & $\checkmark$ & $\checkmark$ & $\checkmark$ \\
\hline Kennie 1988 [35] & & & $\checkmark$ & $\checkmark$ & $\checkmark$ & \\
\hline McGilton 2013 [36] & $\checkmark$ & & & & $\checkmark$ & \\
\hline \multicolumn{7}{|l|}{ Pharmaceuticals } \\
\hline Prieto-Alhambra 2014 [32] & & $\checkmark$ & & & & \\
\hline \multicolumn{7}{|l|}{ Multifactorial assessment and intervention } \\
\hline Shaw 2003 [18] & $\checkmark$ & $\checkmark$ & & & & $\checkmark$ \\
\hline
\end{tabular}

\section{Risk of bias}

Table 4 includes both individual study scores and an overall risk of bias score across studies. Studies generally had a low risk of selection bias, and high risk of performance and detection biases due to difficulties in blinding participants and/or personnel to interventions and outcomes - a common scenario with complex interventions. The risk of bias for attrition and reporting were less clear. Most studies included additional biases such as small numbers of included patients with dementia [33] and low or under-recruitment into the study $[18,34]$ which may have made management of random error difficult. No studies were excluded based on these assessments of risk of bias. Risks of bias forms are available in Additional file 4.

\section{Discussion}

\section{Summary of evidence}

This body of evidence assessing the effectiveness of interventions to improve outcomes for PWD who fall comprised different interventions, reported multiple different outcomes, and included people with cognitive impairment as well as those diagnosed with dementia, making it impossible to pool and difficult to summarise. The quality of evidence was mixed and the results across the studies conflicted even when similar interventions were utilised.

Notably, there were variations in the use of the term 'comprehensive geriatric assessment' (CGA) [33, 34], especially with regards to the types of core staff delivering the intervention. Additionally, key differences occurred in several areas, some thought to have some effect on outcomes, such as the frequency of multidisciplinary team meetings (daily versus twice per week), discharge planning, post-discharge in-home follow-up $[14,22]$, falls assessment and prevention, and medication management [37, 38]. This may be contextual, a result of national, regional or local practices in ageing care, or it may be an indication of a gradually evolving definition of the process itself. Current evidence suggests that CGA is likely to benefit older people hospitalised with acute conditions due to these services generally providing a multidimensional, multidisciplinary approach which includes the identification of medical, social and functional needs, as well as the development of an integrated and coordinated care plan to address those needs $[39,40]$. While CGA has an accepted clinical definition [41], it is known that this interpretation varies widely [42]. The question of whether there is a need for adaptation of CGA for people with dementia has not been addressed.

Nonetheless, several of the studies which focused on providing comprehensive, multidisciplinary in-hospital post-surgical care showed better outcomes for the treatment group. Outcomes were generally short-term, less than 6-months, if they provided any improvement on usual care. In the few instances where it was possible to more directly compare outcomes (e.g. ADLs, length of stay) the results were inconclusive. For example, those in the treatment group in Watne et al. [34] had a significantly longer median length of stay despite statistically insignificant pre-surgical waiting times. We suspect this is likely due to the variance of health care personnel involved, and the actual assessments and interventions used.

Generally, the earlier the patient is mobilised, the better the outcome with regards to reduced length of stay and discharge to independent living. Patients with mild- and moderate dementia also showed better outcomes than those with more severe dementia.

The only intervention which showed a long-term ( $>1$ year) reduction in the number of incident falls was the annual administration of intravenous zoledronic acid [32].

\section{Strengths and limitations}

This review followed established review methodologies including comprehensive searching for evidence and independent risk of bias assessment. 
Table 4 Risk of bias within and across studies

\begin{tabular}{|c|c|c|c|c|c|c|c|}
\hline & $\begin{array}{l}\text { Random sequence } \\
\text { generation } \\
\text { (selection bias) }\end{array}$ & $\begin{array}{l}\text { Allocation } \\
\text { concealment } \\
\text { (selection bias) }\end{array}$ & $\begin{array}{l}\text { Blinding of participants } \\
\text { and personnel } \\
\text { (performance bias) }\end{array}$ & $\begin{array}{l}\text { Blinding of } \\
\text { outcome } \\
\text { assessment } \\
\text { (detection bias) }\end{array}$ & $\begin{array}{l}\text { Incomplete } \\
\text { outcome data } \\
\text { (attrition bias) }\end{array}$ & $\begin{array}{l}\text { Selective reporting } \\
\text { (reporting bias) }\end{array}$ & $\begin{array}{l}\text { Other } \\
\text { bias }\end{array}$ \\
\hline Huusko et al. (2000) [31] & + & + & - & - & + & $?$ & $?$ \\
\hline Kennie et al. (1988) [35] & + & + & - & - & $?$ & $?$ & $?$ \\
\hline McGilton et al. (2013) [36] & - & - & - & - & $?$ & $?$ & - \\
\hline $\begin{array}{l}\text { Prieto-Alhambra et al. } \\
\text { (2014) [32] }\end{array}$ & + & + & + & + & - & + & - \\
\hline Shaw et al. (2003) [18] & + & $?$ & - & - & + & $?$ & $?$ \\
\hline Stenvall et al. (2012) [33] & $?$ & + & - & + & + & $?$ & - \\
\hline Watne et al. (2014) [34] & + & + & - & + & + & + & $?$ \\
\hline Overall score & + & + & - & - & $?$ & $?$ & $?$ \\
\hline
\end{tabular}

Key: + low risk of bias; - high risk of bias;? unclear risk of bias

Four studies that otherwise met the inclusion criteria for this review could not be included [43-46]. The authors of these studies were unsuccessfully contacted either to clarify reported results or to provide sub-group data where it was reported to be available. Three of the studies [43, 45, 46] also used multidisciplinary inhospital post-surgical geriatric assessment which showed improvements in some outcomes within their treatment groups, regardless of mental status.

Due to the heterogeneity of the interventions and outcomes measured, we were unable to perform a meta-analysis. However, it appears that the use of multidisciplinary assessment and intervention shows some improvement in some post-discharge outcomes.

There were three large gaps in the evidence base. Firstly, most of the population presented with hip fracture so interventions may not be applicable to other types of injury, e.g. soft tissue or other types of fracture. Given that most injuries are not fractures and may still be associated with adverse outcomes, there is a need for further research which includes patients whose injury is not a hip fracture. Secondly, and unsurprisingly, given the predominance of interventions for hip fracture, there was no evidence to guide how fall-related injuries should be managed in primary care. Finally, the studies did not show evidence of any particular adaptation of the approach, enhancement of the skills, or composition of multidisciplinary teams given that they were working with a different population from that of older people without a cognitive impairment. Additionally, most of the interventions were not aimed at patients with known dementia; sub-group analysis was used to report the effects of general interventions on this group.

\section{Future directions}

The ability to work with PWD is considered to be a core skill for older people's services, but it may be that further enhancement of the multidisciplinary team both in terms of adapting approach and enhancing skills would lead to further benefits. Further research should target those with a clinical diagnosis of dementia and other types of injury besides hip fracture, and study how the approach of a multidisciplinary team should be adapted to meet the needs of people with dementia.

\section{Conclusions}

Few studies have investigated the effectiveness of interventions specifically for PWD, and those we found assessed different interventions and reported various outcomes, making it difficult to draw firm conclusions. Most post-fall interventions aimed at patients with dementia have shown little efficacy. Minor improvements to some quality of life indicators were shown, but these were generally not statistically significant. Multidisciplinary in-hospital post-surgical assessment and intervention showed the most benefit because patients were discharged earlier and returned to living independently. Intravenous zoledronic acid appears to benefit cognitively impaired individuals who are expected to live beyond 6 months postfracture by reducing recurrence of fracture. There is a need to design RCTs to address all types of injury in people with dementia. Such trials need to consider the views of PWD and their carers with respect to the design and adaptability of the intervention to the person with dementia and also in determining important outcomes to be measured.

\section{Endnotes}

${ }^{1}$ MMSE scores are generally broken down in the following ranges: $0-9=$ severe dementia, $10-19=$ moderate dementia, $20-23$ = mild dementia, $24+=$ fully cognitively intact. However, Huusko et al. [29] reported the scores as $0-11,12-17,18-23$, and 24-30. 


\section{Additional files}

Additional file 1: PRISMA Checklist. (PDF $331 \mathrm{~kb}$ )

Additional file 2: Medline (OVID) sample search strategy. (PDF 83 kb)

Additional file 3: Full summary table of interventions utilised in geratric assessment. (PDF $191 \mathrm{~kb}$ )

Additional file 4: Risk of bias assessment within individual studies. (PDF $71 \mathrm{~kb}$ )

\section{Abbreviations}

A\&E: Accident and emergency; ADL: Activities of daily living; BADL: Barthel Activities of Daily Living; CGA: Comprehensive geriatric assessment; I/ C: Intervention/control; IQR: Interquartile range; MMSE: Mini Mental State Exam; NEADL: Nottingham Extended Activities of Daily Living Index; P-ADL: Personal/Primary Activities of Daily Living; PWD: People with dementia; SPMSQ: Short Portable Mental Status Questionnaire

\section{Acknowledgements}

We would like to thank Professor Lynn Rochester at the Institute of Neuroscience, Newcastle University; Dr. Robert Barber, Honorary Clinical Senior Lecturer at the Institute of Neuroscience, Newcastle University; Dr. Steve Parry, Clinical Senior Lecturer and Consultant at the Institute of Cellular Medicine, Newcastle University; and Dawn Craig, Principal Scientist at the Institute of Health and Society, Newcastle University, for comments and feedback on the draft of this manuscript. Professor Rochester, Dr. Barber, and Dr. Parry also provided support in obtaining funding and for the overall design of the HTA study.

\section{Funding}

This paper forms part of a project funded by the National Institute for Health Research (NIHR) Health Technology Assessment (HTA) Programme (project number HTA-13/78/02) and will be published in full in the journal Health Technology Assessment. The views expressed are those of the authors and not necessarily those of the NHS, the NIHR, or the Department of Health. Further information available at http://research.ncl.ac.uk/difrid/.

\section{Availability of data and materials}

All data generated and/or analysed during this study are available from the corresponding author on reasonable request.

\section{Authors' contributions}

LMA secured funding, developed the research question, and designed the overall study, acted as a third reviewer, and assisted with drafting and reviewing the manuscript. SR developed the search strategy with LMA, ran the searches, abstracted and analysed data, and wrote the first draft of this manuscript. SBN abstracted and analysed data, developed tables, and assisted with drafting and reviewing the manuscript. FRB developed the data extraction form, abstracted and analysed data, and assisted with drafting and reviewing the manuscript. CF developed the research question, acted as third reviewer, and assisted with drafting and reviewing the manuscript. All authors read and approved the final manuscript.

\section{Ethics approval and consent to participate}

Not applicable.

\section{Consent for publication}

Not applicable.

\section{Competing interests}

The authors declare that they have no competing interests.

\section{Publisher's Note}

Springer Nature remains neutral with regard to jurisdictional claims in published maps and institutional affiliations.

\section{Author details}

${ }^{1}$ Present Address: Kaiser Permanente Research Affiliates, Evidence-based Practice Center, Center for Health Research, Portland, OR, USA. ${ }^{2}$ Institute of
Health and Society, Newcastle University, Newcastle upon Tyne, UK. ${ }^{3}$ Dementia Research Collaborative Norwich Medical School, University of East Anglia, Norwich, UK. ${ }^{4}$ Norfolk and Suffolk NHS Foundation Trust, Norwich, UK ${ }^{5}$ Institute of Neuroscience, Newcastle University, Newcastle upon Tyne, UK.

Received: 30 October 2017 Accepted: 13 February 2018

Published online: 20 February 2018

\section{References}

1. Prince $M$, Knapp $M$, Guerchet $M$, McCrone P, Prina M, Comas-Herrera A, Wittenberg R, Adelaja B, Hu B, King D, et al. Dementia UK: update-second edition. London: Alzheimer's Society; 2014.

2. Matthews FE, Arthur A, Barnes LE, Bond J, Jagger C, Robinson L, Brayne C. A two-decade comparison of prevalence of dementia in individuals aged 65 years and older from three geographical areas of England: results of the cognitive function and ageing study I and II. Lancet. 2013;382(9902): 1405-12.

3. Seitz DP, Adunuri N, Gill SS, Rochon PA. Prevalence of dementia and cognitive impairment among older adults with hip fractures. J Am Med Dir Assoc. 2011;12(8):556-64.

4. Allan LM, Ballard CG, Rowan EN, Kenny RA. Incidence and prediction of falls in dementia: a prospective study in older people. PLoS One. 2009:4(5): e5521.

5. Harvey L, Mitchell R, Brodaty H, Draper B, Close J. Differing trends in fallrelated fracture and non-fracture injuries in older people with and without dementia. Arch Gerontol Geriatr. 2016;67:61-7.

6. Shaw FE. Falls in cognitive impairment and dementia. Clin Geriatr Med. 2002;18(2):159-73.

7. Voisin T, Sourdet S, Cantet C, Andrieu S, Vellas B. Descriptive analysis of hospitalizations of patients with Alzheimer's disease: a two-year prospective study of 686 patients from the REAL.FR study. J Nutr Health Aging. 2009; 13(10):890-2.

8. Rowe MA, Fehrenbach N. Injuries sustained by community-dwelling individuals with dementia. Clin Nurs Res. 2004;13(2):98-110. discussion 111-116

9. Vu T, Finch CF, Day L. Patterns of comorbidity in community-dwelling older people hospitalised for fall-related injury: a cluster analysis. BMC Geriatr. 2011;11:45.

10. Clevenger CK, Chu TA, Yang Z, Hepburn KW. Clinical care of persons with dementia in the emergency department: a review of the literature and agenda for research. J Am Geriatr Soc. 2012;60(9):1742-8.

11. Smith TO, Hameed YA, Cross JL, Henderson C, Sahota O, Fox C. Enhanced rehabilitation and care models for adults with dementia following hip fracture surgery. Cochrane Database Syst Rev. 2015;(6):Cd010569.

12. Hedman AM, Grafstrom M. Conditions for rehabilitation of older patients with dementia and hip fracture - the perspective of their next of kin. Scand J Caring Sci. 2001;15(2):151-8.

13. Vaapio SS, Salminen MJ, Ojanlatva A, Kivela SL. Quality of life as an outcome of fall prevention interventions among the aged: a systematic review. Eur J Pub Health. 2009;19(1):7-15.

14. Gillespie LD, Robertson MC, Gillespie WJ, Sherrington C, Gates S, Clemson LM, Lamb SE. Interventions for preventing falls in older people living in the community. Cochrane Database Syst Rev. 2012;(9):Cd007146.

15. National Institute for Health and Clinical Excellence. Falls in older people: assessing risk and prevention [CG161]. London: NICE; 2013.

16. Winter $H$, Watt $K$, Peel NM. Falls prevention interventions for communitydwelling older persons with cognitive impairment: a systematic review. Int Psychogeriatr. 2013;25(2):215-27.

17. Jensen J, Lundin-Olsson L, Nyberg L, Gustafson Y. Fall and injury prevention in older people living in residential care facilities. A cluster randomized trial. Ann Intern Med. 2002;136(10):733-41.

18. Shaw FE, Bond J, Richardson DA, Dawson P, Steen IN, McKeith IG, Kenny RA Multifactorial intervention after a fall in older people with cognitive impairment and dementia presenting to the accident and emergency department: randomised controlled trial.[erratum appears in BMJ. 2003 Mar 29:326(7391):699]. BMJ. 2003:326(7380):73.

19. Buchner DM, Larson EB. Falls and fractures in patients with Alzheimer-type dementia. JAMA. 1987;257(11):1492-5.

20. Asada T, Kariya T, Kinoshita T, Asaka A, Morikawa S, Yoshioka M, Kakuma T. Predictors of fall-related injuries among community-dwelling elderly people with dementia. Age Ageing. 1996;25(1):22-8. 
21. Ballard CG, Shaw F, Lowery K, McKeith I, Kenny R. The prevalence, assessment and associations of falls in dementia with Lewy bodies and Alzheimer's disease. Dement Geriatr Cogn Disord. 1999;10(2):97-103.

22. Harlein J, Dassen T, Halfens RJ, Heinze C. Fall risk factors in older people with dementia or cognitive impairment: a systematic review. J Adv Nurs. 2009;65(5):922-33.

23. Booth V, Hood V, Kearney F. Interventions incorporating physical and cognitive elements to reduce falls risk in cognitively impaired older adults: a systematic review. JBI Database System Rev Implement Rep. 2016;14(5):110-35.

24. Jensen $L$, Padilla R. Effectiveness of environment-based interventions that address behavior, perception, and falls in people with Alzheimer's disease and related major neurocognitive disorders: a systematic review. Am J Occup Ther. 2017;71(5):7105180030p7105180031-10.

25. Lach HW, Harrison BE, Phongphanngam S. Falls and fall prevention in older adults with early-stage dementia: an integrative review. Res Gerontol Nurs. 2017;10(3):139-48

26. Muir SW, Gopaul K, Montero Odasso MM. The role of cognitive impairment in fall risk among older adults: a systematic review and meta-analysis. Age Ageing. 2012;41(3):299-308.

27. Beyer F, Robalino S, Fox C, Rochester L, Parry S, Barber R, Allan L. Effectiveness of interventions aimed at improving physical and psychological outcomes of fall-related injuries in people with dementia, PROSPERO: International prospective register of systematic reviews; 2016. p. CRD42016029565

28. Moher D, Liberati A, Tetzlaff J, Altman DG, Prisma Group. Preferred reporting items for systematic reviews and meta-analyses: the PRISMA Statement. PLoS Med. 2009;6(7):e1000097.

29. Hartling L, Featherstone R, Nuspl M, Shave K, Dryden DM, Vandermeer B. The contribution of databases to the results of systematic reviews: a crosssectional study. BMC Med Res Methodol. 2016;16(1):127.

30. Higgins J, Altman D, Sterne J. Chapter 8: assessing risk of bias in included studies. In: Higgins J, Green S, editors. Cochrane Handbook for Systematic Reviews of Interventions, vol. vol. Version 5.1.0 (updated March 2011): The Cochrane Collaboration; 2011.

31. Huusko TM, Karppi P, Avikainen V, Kautiainen H, Sulkava R. Randomised, clinically controlled trial of intensive geriatric rehabilitation in patients with hip fracture: subgroup analysis of patients with dementia. BMJ. 2000; 321(7269):1107-11.

32. Prieto-Alhambra D, Judge A, Arden NK, Cooper C, Lyles KW, Javaid MK. Fracture prevention in patients with cognitive impairment presenting with a hip fracture: secondary analysis of data from the HORIZON Recurrent Fracture Trial. Osteoporos Int. 2014;25(1):77-83.

33. Stenvall M, Berggren M, Lundstrom M, Gustafson Y, Olofsson B. A multidisciplinary intervention program improved the outcome after hip fracture for people with dementia-subgroup analyses of a randomized controlled trial. Arch Gerontol Geriatr. 2012;54(3):e284-9.

34. Watne LO, Torbergsen AC, Conroy S, Engedal K, Frihagen F, Hjorthaug GA, Juliebo V, Raeder J, Saltvedt I, Skovlund E, et al. The effect of a pre- and postoperative orthogeriatric service on cognitive function in patients with hip fracture: randomized controlled trial (Oslo Orthogeriatric Trial). BMC Med. 2014;12:63

35. Kennie DC, Reid J, Richardson IR, Kiamari AA, Kelt C. Effectiveness of geriatric rehabilitative care after fractures of the proximal femur in elderly women - a randomized clinical-trial. Br Med J. 1988;297(6656):1083-6.

36. McGilton KS, Davis AM, Naglie G, Mahomed N, Flannery J, Jaglal S, Cott C, Stewart S. Evaluation of patient-centered rehabilitation model targeting older persons with a hip fracture, including those with cognitive impairment. BMC Geriatr. 2013;13:136.

37. Sterke CS, van Beeck EF, van der Velde N, Ziere G, Petrovic M, Looman CW, van der Cammen TJ. New insights: dose-response relationship between psychotropic drugs and falls: a study in nursing home residents with dementia. J Clin Pharmacol. 2012;52(6):947-55.

38. Sri-On J, Tirrell GP, Bean JF, Lipsitz LA, Liu SW. Revisit, subsequent hospitalization, recurrent fall, and death within 6 months after a fall among elderly emergency department patients. Ann Emerg Med. 2017;70(4):516521.e512.

39. Parker SG, McLeod A, McCue P, Phelps K, Bardsley M, Roberts HC, Conroy SP. New horizons in comprehensive geriatric assessment. Age Ageing. 2017; 46(5):713-21.

40. Pilotto A, Cella A, Pilotto A, Daragjati J, Veronese N, Musacchio C, Mello AM, Logroscino G, Padovani A, Prete C, et al. Three Decades of Comprehensive
Geriatric Assessment: Evidence Coming From Different Healthcare Settings and Specific Clinical Conditions. J Am Med Dir Assoc. 2017:18(2):192.e191-11.

41. Rubenstein $L Z$, Stuck $A E$, Siu AL, Wieland D. Impacts of geriatric evaluation and management programs on defined outcomes: overview of the evidence. J Am Geriatr Soc. 1991;39(9 Pt 2):8S-16S. discussion 17S-18S

42. Parker SG, McCue P, Phelps K, McCleod A, Arora S, Nockels K, Kennedy S, Roberts $\mathrm{H}$, Conroy S. What is comprehensive geriatric assessment (CGA)? An umbrella review. Age Ageing. 2018;47(1):149-55.

43. Deschodt M, Braes T, Broos P, Sermon A, Boonen S, Flamaing J, Milisen K. Effect of an inpatient geriatric consultation team on functional outcome, mortality, institutionalization, and readmission rate in older adults with hip fracture: a controlled trial. J Am Geriatr Soc. 2011;59(7):1299-308.

44. Huusko TM, Karppi P, Kautiainen H, Suominen H, Avikainen V, Sulkava R. Randomized, double-blind, clinically controlled trial of intranasal calcitonin treatment in patients with hip fracture. Calcif Tissue Int. 2002;71(6):478-84.

45. Prestmo A, Saltvedt I, Helbostad JL, Taraldsen K, Thingstad P, Lydersen S, Sletvold $\mathrm{O}$. Who benefits from orthogeriatric treatment? Results from the Trondheim hip-fracture trial. BMC Geriatr. 2016;16:49.

46. Vidan M, Serra JA, Moreno C, Riquelme G, Ortiz J. Efficacy of a comprehensive geriatric intervention in older patients hospitalized for hip fracture: a randomized, controlled trial. J Am Geriatr Soc. 2005;53(9):1476-82.

47. University of Texas School of Public Health. Search filters for case-control studies and clinical trials. http://libguides.sph.uth.tmc.edu/ovid_medline_ filters. Accessed 18 Jan 2018

\section{Submit your next manuscript to BioMed Central and we will help you at every step:}

- We accept pre-submission inquiries

- Our selector tool helps you to find the most relevant journal

- We provide round the clock customer support

- Convenient online submission

- Thorough peer review

- Inclusion in PubMed and all major indexing services

- Maximum visibility for your research

Submit your manuscript at www.biomedcentral.com/submit
) Biomed Central 